\title{
EFFECT OF COMPETITION ANXIETY ON ATHLETES SPORTS PERFORMANCE: IMPLICATION FOR COACH
}

\author{
Noor Muhammad Marwat ${ }^{*}$, Syed Zia ul Islam², Muhammad Safdar Luqman ${ }^{3}$, Mehwish Manzoor ${ }^{4}$, Irfanullah $^{5}$ \\ ${ }^{1 *}$ Lecturer, Department of Sports Sciences and Physical Education, Gomal University D.I Khan, Pakistan; ${ }^{2}$ Associate \\ Professor, University of Huripur, Pakistan; ${ }^{3}$ Senior Instructor Physical Education, Elementary and Secondary Education, \\ KP, Pakistan; ${ }^{4}$ Ph.D., Scholar, Department of Physical Education, University of Sindh Jamshoro, Pakistan; ${ }^{5}$ Assistant \\ Professor, Higher Education Department, KP, Pakistan. \\ Email: ${ }^{1 *}$ marwatnoor@yahoo.com, ${ }^{2}$ szislam@gu.edu.pk, ${ }^{3}$ safdarkhan821@gmail.com, \\ ${ }^{4}$ mehwishmanzoor233@yahoo.com, 5 irfanullah949@gmail.com
}

Article History: Received on $18^{\text {th }}$ June 2021, Revised on $26^{\text {th }}$ June 2021, Published on $29^{\text {th }}$ June 2021

\begin{abstract}
Purpose: The purpose of this study was to determine the effect of competition anxiety upon sports performance of elite athletes who took part in the "31st National Games held in Khyber Pakhtunkhwa's (KP), Pakistan.

Methodology: One hundred and twenty-eight $(\mathrm{N}=128)$ males $=88$, females $=40$; Age $21.9+/-1.5$ years; Sports Experience, $8.9+/-1.7$ years) provided the required information on 15-items Sports Competition Anxiety Test (SCAT). The history of sports performance of athletes was obtained during breaks within competitive fixtures.

Main Findings: The analyzed data revealed that competitive anxiety is responsible for $38 \%$ change in sports performance. Furthermore, the relationship is moderate negative identifying that an increase in competitive anxiety decreases the sports performance of athletes $(\mathrm{r}=-0.386, \mathrm{P}=.002)$. Additionally, comparative analyses indicated that female athletes and athletes from individual sports showed higher levels of Competition Anxiety, while male athletes and athletes with team sport reported lower levels of Competition Anxiety $(\mathrm{P}<.005)$.
\end{abstract}

Implications of the study: This gender impact is critical and significant showing decisive implications for the coaches and trainers. These findings were explored in light of the theoretical and practical implications of these findings for designing sport psychology programs in Pakistan for athletes from various contexts.

Novelty: The findings indicate that competitive trait anxiety can harm the success, and indicate that certain PL athletes can benefit from therapies that seek to decrease anxiety before and during competition.

Keywords: Effect, Competition Anxiety, Athletes Performance, Implication, Coach.

\section{INTRODUCTION}

Sports psychologists believe that high levels of competitive state anxiety and trait anxiety before and during competition are harmful, badly affecting the performance and even leading to expulsion from the event. Anxiety in sport is most common and it is mostly responsible for stress in competitive environments. Anxiety and stress in sport are more complex and complicated aspects that is why it has been proved difficult for the experts to define it accurately but the definition offered by sport psychology consultant Dr. Graham Jones in his book has an interesting and well-directed version, that anxiety is developed in the competitors due to the interaction between the athlete and the environment. Anxiety develops a feeling of apprehension and heightened physiological arousal. It is present in all human beings; some individuals try to avoid this feeling, and thus it ultimately produces fear. Fear is dangerous and it may produce adverse consequences, anxiety compels a person to enhance his/her performance thereby contributing to the person's success and achievement.

Anxiety is dynamic and it leads the individual's passion towards an effective role in his performance. The researchers have tried time and again to understand the phenomenon that how anxiety affects performance before and during competition. Various sports competitions have the potential for causing high levels of stress and anxiety; it is wellestablished fact that proper application of the psychological strategies when applied/practiced can be beneficial in anxiety and stress management. The results of various studies have shown that anxiety can play a vital role in sports injury control, occurrence, recovery, and the continuum of the sport process (Edvardsson, A., Ivarsson, A., \& Johnson, 2012; Kleinert, 2002). Anxiety is a psychological and physiological state with the cognitive, trait, state, and emotional aspects (Seligman, Walker \& Rosenhan, 2001).

Anxiety is perceived as an emotion that is characterized by anxious feelings, worried thoughts, and physical changes such as elevated blood pressure. Usually, anxiety is considered an unpleasant condition in response to perceived stress about the execution of a task under pressure (Pijpers, Oudejans, \& Bakker, 2005). Anxiety is a common emotional condition which athletes experience at all levels of their sports performance (Lundqvist, 2006). Competitive state anxiety arises when the sport's expectations are greater than abilities perceived by the athletes. While a bit of anxiety before a game gives us the push we need to address challenges, uncontrolled anxiety can damage your ring performance (Bali, 2015).

In competitions, anxiety is expected where interactions with the opponent before the game is greater, and it became more 
effective (Craft et al., 2003). In the study which was focusing on penalty kick soccer players, anxiety proved to cause the participants to focus on the opponent goalkeeper. Results reflected that a more centrally fixation point led to a more misdirected shot, making it easier for the goalkeeper to tackle. The size or type of audience, starving to maintain or win a position, or expectation of negative criticism are directly associated with anxiety (Wilson, Wood \& Vine, 2009).

The researchers have tried to seek understanding how a particular style of goal pursuit called linking is related to depression symptoms, pre-competition, and during competition anxiety in national level athletes of Pakistan, participating in different episodes of national games. Goal theory is the most important aspect of participation in various sport and the researcher has focused upon the goal theory in the athletic population of Pakistan. Linking of athlete's interest with their goal setting and depression was tried to calculate through Sport competition anxiety in the athletes who participated in different national games of Pakistan.

Anxiety is dynamic and it leads the individual's passion towards an effective role in his performance. The researchers have tried time and again to understand the phenomenon that how anxiety affects performance before and during competition. Various sports competitions have the potential for causing high levels of stress and anxiety; it is wellestablished fact that proper application of the psychological strategies when applied/practiced can be beneficial in anxiety and stress management. The results of various studies have shown that anxiety can play a vital role in sports injury control, occurrence, recovery, and the continuum of the sport process (Edvardsson, A., Ivarsson, A., \& Johnson, 2012; Kleinert, 2002). Anxiety is a psychological and physiological state with a cognitive, trait, state, and emotional aspect (Seligman, Walker \& Rosenhan, 2001).

\section{OBJECTIVES OF THE STUDY}

1. To determine the effect predictor (Competitive Anxiety) on Criterion variable (Sports Performance).

2. To evaluate the association of predictor (Competitive Anxiety) on Criterion variable (Sports Performance).

3. To measure the comparative analysis of the (SCAS) by gender (females vs males).

4. To analyze the Comparative analysis of the (SCAS) by the format of sport (individual vs team).

\section{LITERATURE REVIEW}

In the growing field of sport psychology, various studies on the effect of mental toughness, emotions, sadness, and worries on sport and athletics performance have been conducted. A player may face a wide range of negative feelings prior to competition which may badly harm the performance. Such pre-game feeling is called anxiety. According to, Craft, Magyar, and Feltz, (2003) anxiety is a feeling of unknown stress in an athlete's abilities and the results expected from him. Some levels of anxiety for the competition actually improve the skills and abilities of the participants (Mottram, 2005). A study of anxiety conducted on 15 ballet dancers, proved that the presence of anxiety was important to increase concentration level and energy in the subjects. The respondents opined that there was a level of anxiety that negatively affected their performance. The results show that cognitive anxiety had a greater effect on the performance as compared to the somatic component (Walker \& Nordin-Bates, 2010).

The competition anxiety has state effects on the athletes which are converted to trait anxiety during the competition (Athan \& Sampson, 2013). During sports competitions, most of the players are the victim of anxiety which may worsen their performance (Farnendez-Fernandez, 2014). In sports competitions where success and failure are involved why some of the players are unable to maintain their concentration level and may feel anxiety. The players feel anxious before as well during competitions (Chiariotti, et al., 2016). The experience of the athletes is the factor that may lessen the effects of anxiety on the performance of the athletes. The role of experience is second to none in coping the anxiety (Whitley, 2013). The anxiety level of the non-athlete is almost observed to be high in the Athletics competitions and it harms the performance of the athlete (Lence, et al., 2016). Anxiety is an integral part of the competition and its adverse effects are prominent in all kinds of athletes (Oureshi, 2015). The athletes taking part in both the track and field events are prone to anxiety and its effects (Ibrahim \& Almoslim 2016). Naturally, every fight, combat, and competition has its reaction on the participant and the effect to that is called anxiety which is reflected in the players. Anxiety has effects on the players according to their potential and power of sustainability (Ramis, Viladrich, Sousac \& Jannes, 2015). The effects of anxiety on the athlete's performance are universally accepted, (Radzi, Yousaf, \& Zakaria, 2013).

\section{HYPOTHESIS}

Ho 1: The predictor (Competitive Anxiety) has a negative effect on the Criterion variable (Sports Performance)

Ha 2: Competition anxiety is negatively associated with sports performance.

Ha 3: The female athletes have produced higher scores on (SCAS) as compared to male athletes.

Ha 4: The athletes participated in individual sport have produced higher score on (SCAS) compared to those who participated in a team sport. 


\section{RESEARCH METHODOLOGY}

\section{Research Method}

Different methods and procedures are used for the collection of data required to test the hypotheses or answer the questions. These methods play a distinctive role in describing and quantifying the data. According to Best and Kahn, (2016), every method is particularly appropriate for certain sources of data, encompassing information of the type and in the form that can be most effectively used. Henceforth, the researcher employed a quantitative research method for describing the responses of the subjects.

\section{Participants}

In a research study, a sample is a group from which the desired information is obtained, whereas the population is the larger group to which the researcher hopes to apply the results. All the athletes who had participated in the last two years' national games of Pakistan constituted a population for this study. In research, visiting or contacting the entire population was a difficult job for the researchers; therefore, the researcher selected a sample of 126 athletes to whom the researcher distributed questionnaires to collect the requisite information. According to Hinton (2005), a sample of 10\% is acceptable in survey research. Consequently, a sample of 126 athletes from the total population of 1026 (10\% of 1026) participated in the study.

\section{Instrument}

Sports Competition Anxiety Test (SCAT) was used to obtain the required information from the participants. The SCAT is a 15-item instrument designed to measure the amount of anxiety an athlete experiences before a competition. This instrument was previously validated in a variety of environments. Martens et al. (13) demonstrated evidence of high internal consistency on the SCAT (Kuder-Richardson Formula 20 (KR-20) values ranging from .95 to .97) and test-retest reliability $(\mathrm{M}$ retest reliability $=.77)$.

\section{DATA ANALYSIS}

The collected data were then tabulated and analyzed using appropriate statistical techniques. Linear regression, Pearson Correlation and, Independent Sample t-Test were applied to test the set hypotheses of the study.

\section{Results}

Ho 1: The predictor (Competitive Anxiety) has a negative effect on the Criterion variable (Sports Performance)

Table 1: A Linear regression model showing the influence of predictor upon criterion variable

\begin{tabular}{lccccccc}
\hline Testing Variables & R & R2 & $\begin{array}{c}\text { Adjust } \\
\text { R2 }\end{array}$ & $\begin{array}{c}\text { Std. } \\
\text { Err }\end{array}$ & Beta & t & Sig. \\
\hline Sport performance & .621 & .385 & .373 & .52707 & -.368 & -11.371 & .002 \\
\hline
\end{tabular}

Significant at .05 .

The results show that $38 \%$ of the change in sports performance is due to competition anxiety and significant $(\mathrm{R} 2=$ $.385)$. In addition, the negative relationship indicated that an increase in predictor competitive anxiety decreases the score of the criterion variable (sports performance). Therefore, HO 1 is accepted.

Ha 2: Competition anxiety is negatively associated with sports performance.

Table 2: Pearson correlation showing the association of competition anxiety and sports performance

\begin{tabular}{cccc}
\hline \multicolumn{2}{c}{ Testing Variables } & $\begin{array}{c}\text { Pre-competition } \\
\text { Anxiety }\end{array}$ & Sports Performance \\
\hline Pre-competition Anxiety & Pearson-Correlation & & -0.368 \\
\hline & Sig. (2-tailed) & 128 & 0.03 \\
\hline & $\mathrm{N}$ & -0.368 & \\
\hline Sports Performance & Pearson-Correlation & 0.03 \\
\hline & Sig. (2-tailed) & 128 & \\
\hline Sig at 0.01(2-tailed) & $\mathrm{N}$ & & \\
\hline
\end{tabular}

Pearson correlation was applied to find out the association between competition anxiety and sports performance. The analyzed statistical inferences revealed a negative moderate correlation between competition anxiety and performance (p: 0.03 , r: -0.368). Table \# 3:

Ha 3: Comparative analysis of the (SCAS) by gender (females vs males) 
Table 3: Independent Sample t-Test is showing the difference of SCAS

\begin{tabular}{|c|c|c|c|c|}
\hline By Sex & $\mathbf{N}$ & Mean Std. D & DF & Sig. \\
\hline Individual Sport & 88 & $\begin{array}{ll}1.88 & 0.56 \\
\end{array}$ & 126 & \\
\hline Team Sport & 40 & $\begin{array}{ll}1.66 & 0.60 \\
\end{array}$ & 8.12 & .003 \\
\hline
\end{tabular}

Significant at .05.

The Independent Sample t-Test results by sex (male and female) are showing in Table 3. It was found that this variable had a significant difference in competitive anxiety. The subsequent univariate analysis permitted verification that the female revealed higher levels of competitive anxiety $(\mathrm{p}<.013)$.

Ha 3: Comparative analysis of the (SCAS) by the format of sport (individual vs team).

Table 4: Independent Sample t-Test is showing the difference of SCAS by the format of the sport

\begin{tabular}{|c|c|c|c|c|}
\hline Testing Variables & $\mathbf{N}$ & Mean Std. D & DF & Sig. \\
\hline Individual Sport & 88 & $1.60 \quad 0.61$ & 126 & .003 \\
\hline Team Sport & 40 & $1.80 \quad 0.56$ & 8.12 & .003 \\
\hline
\end{tabular}

Significant at .05 .

The Independent Sample t-Test results by the format of sport (individual vs team) are presented in Table 4. Generally, it was verified that this variable had a significant difference in competitive anxiety based on the format of the sport. The subsequent univariate analysis permitted verification that the team sport- participants reveal higher levels of competitive anxiety $(\mathrm{p}<.003)$.

\section{DISCUSSION}

This study was carried out to determine the effect of competitive anxiety on the sports performance of elite athletes of Pakistan. The study measured the differences on the Competitive Sports Anxiety Scale (CSAS) based on their gender and format of Sport.

The first and second hypotheses found that the Criterion Variable (Competitive Sports Anxiety) has produced negative influence and moderate negative correlation with Criterion Variable (Sports Performance) was supported by the results as shown in Table $1 \& 2$. These findings are supported by the studies as identified that negative correlation between cognitive anxiety and sports performance among football players and track and field (Parnabas, Parnabas, \& Parnabas, 2015; Parnabas, Parnabas, \& Parnabas, 2015). These findings have paramount significance to guide the intervention program of sports psychologists and sports coaches. When they aim to help athletes in controlling their anxiety, it is important to evaluate the dimensions that constitute the athletes' "perceived threats," which are of fundamental importance to interventions of sport psychology.

The third and fourth hypotheses concerning the comparative analysis of athletes on (SCAS) based on their gender and format of the sport, and the results indicated that female athletes and athletes from individual sports showed higher levels of Competition Anxiety, while male athletes and athletes with team sport reported lower levels of Competition Anxiety. The individual athletes showed lower scores of cognitive distress in terms of sport form than the athletes for team sports. The belief that the athlete has a higher degree of control that he/she exercises over what he/she can do during the competition will explain this result in part. These findings corroborate the previous findings of international studies. Generally, sex had a significant effect on the competitive anxiety of the athletes, in accordance with the results of (Abrahamsen, Roberts, \& Pensgaard, 2008; Ramis, Viladrich, Sousa, Jannes, 2015).

\section{CONCLUSION}

The study indicated that sports competition anxiety has produced a negative effect and results of this study involving Pakistani athletes indicate that SCAS is negatively correlated with their sports performance. Furthermore, comparative analyses indicate that male athletes have produced a slighter score on SCAS compared to female athletes. In addition, the comparative analysis indicated that those athletes who participated in team sport scored higher scores on SCAS compared to those who participated in an individual sport. These findings suggest the influence of the demographic and contextual variables studied, constituting important references for future interventions centered on improving these athletes' sports performance.

\section{LIMITATION}

The sample for this research paper was selected from athletes those who took part in the " 31 st National Games held in Khyber Pakhtunkhwa's (KP), Pakistan. Therefore, this can limit the application of results to other educational institutions and other settings as well.

\section{ACKNOWLEDGEMENT}

Thank you to the higher education Commission and Gomal University Dera Ismail Khan of Pakistan who has provided 
research guidelines to the research team.

\section{AUTHOR'S CONTRIBUTION}

Noor Muhammad Marwat ${ }^{*}$, Dr. Syed Zia-ul-Islam², Muhammad Safdar Luqman ${ }^{3}$, Mehhwish Manzoor $^{4}$, Irfanullah $^{5}$ :

Authors' Contribution: 1 - Study design; 2 - Data collection; 3- Statistical analysis; 4 - Manuscript preparation; 5Funds collection.

\section{REFERENCES}

1. Abrahamsen, F. E., Roberts, G. C., \& Pensgaard, A. M. (2008). Achievement goals and gender effects on multidimensional anxiety in national elite sport. Psychology of Sport and Exercise, 9(4), 449-464. https://doi.org/10.1016/j.psychsport.2007.06.005

2. Bali, A. (2015). Psychological factors affecting sports performance. International Journal of Physical Education, Sports and Health, 1(6), 92-95.

3. Battaglia, M., Sampling, N., \& Lavrakas, P. J. (2008). Encyclopedia of survey research methods.

4. Best, J. W., \& Kahn, J. V. (2016). Research in education. Pearson Education India.

5. Chiariotti, L., Coretti, L., Pero, R., \& Lembo, F. (2016). Epigenetic alterations induced by bacterial lipopolysaccharides. In Patho- Epigenetics of Infectious Disease (pp. 91-105). Springer, Cham. https://doi.org/1 0.1007/978-3-319-24738-0 5

6. Craft, L. L., Magyar, T. M., Becker, B. J., \& Feltz, D. L. (2003). The relationship between the Competitive State Anxiety Inventory-2 and sport performance: A meta-analysis. Journal of Sport \& Exercise Psychology, 25(1), 44-65. https://doi.org/10.1123/jsep.25.1.44

7. Edvardsson, A., Ivarsson, A., \& Johnson, U. (2012). Is a cognitive- behavioural biofeedback intervention useful to reduce injury risk in junior football players?. Journal of sports science \& medicine, 11(2), 331.

8. Fernández-Fernández, J., Boullosa, D. A., Sanz-Rivas, D., Abreu, L., Filaire, E., \& Mendez-Villanueva, A. (2015). Psychophysiological stress responses during training and competition in young female competitive tennis players. International Journal of Sports Medicine, 36(01), 22- 28.Athan, A. N. \& Sampson, U. I. (2013). Coping with pre- competitive anxiety in sport competition. European Journal of Natural and Applied Sciences, 1(1), 1-9. https://doi.org/10.1055/s-0034-1384544

9. Ibrahim, S., \& Almoslim, H. A. (2016). State anxiety and self-efficacy among track and field low and high performers. Indian Journal of Science and Technology, 9(7). https://doi.org/10.17485/ijst/2016/v9i7/81884

10. Kleinert, J. (2002). Causative and protective effects of sport injury trait anxiety on injuries in German University sport. European Journal of Sport Science, 2(5), 1-12. https://doi.org/10.1080/17461390200072503

11. Lence, A., Velickovska, L., Damovska, I., Inastastasovski, T. (2016). Anxiety between athletes and nonathletes", Research in Physical Education, Sport and Health, 3(1), 59-61.

12. Lundqvist, C. (2006). Competing under pressure: State anxiety, sports performance and assessment (Doctoral dissertation, Psykologiska institutionen). https://doi.org/10.1037/e530252013-001

13. Martens, R. (1977). Sport competition anxiety test. https://doi.org/10.1037/t27556-000

14. Martens, R., Vealey, R. S., \& Burton, D. (1990). Competitive anxiety in sport. Human kinetics.

15. Parnabas, V., Parnabas, J., \& Parnabas, A. M. (2015). The effect of cognitive anxiety on sport performances among football players. The International Journal of Indian Psychology, 2, 1-8. https://doi.org/10.13189/ujp .2014 .020204

16. Parnabas, V., Parnabas, J., \& Parnabas, A. M. (2015). The Effect of Cognitive Anxiety on Sport Performance among Track and Field Athletes. Int J Indian Psychol, 2, 40-47. https://doi.org/10.13189/ujp.2014.020204

17. Pijpers, J. R., Oudejans, R. R., \& Bakker, F. C. (2005). Anxiety-induced changes in movement behaviour during the execution of a complex whole-body task. The Quarterly Journal of Experimental Psychology Section A, 58(3), 421-445. https://doi.org/10.1080/02724980343000945

18. Qureshi, D. R. (2015). Comparative Study of Anxiety Test between College Level Table Tennis and Volleyball Players. Scholars Impact, 2(1), 41-44.

19. Radzi, J. A., Yusof, S. M., \& Zakaria, A. A. (2013). Pre-competition anxiety levels in individual and team sport athletes. In Proceeding of the International Conference on Social Science Research (pp. 1197-1206).

20. Ramis, Y., Viladrich, C., Sousa, C., \& Jannes, C. (2015). Exploring the factorial structure of the Sport Anxiety Scale-2: Invariance across language, gender, age and type of sport. Psicothema, 27(2), 174-181.

21. Ramis, Y., Viladrich, C., Sousa, C., \& Jannes, C. (2015). Exploring the factorial structure of the Sport Anxiety Scale-2: Invariance across language, gender, age and type of sport. Psicothema, 27(2).

22. Walker, I. J., \& Nordin-Bates, S. M. (2010). Performance anxiety experiences of professional ballet dancers: The importance of control. Journal of Dance Medicine \& Science, 14(4), 133-145. Whiteley, G. (2013). How Trait and State Anxiety Influence Athletics Performance (Doctoral dissertation, Wittenberg University).

23. Wilson, M.R., Vine, S.J., \& Wood, G. (2009). The influence of anxiety on visual attentional control in basketball free-throw shooting. Journal of Sport \& Exercise Psychology, 31, 152-168. https://doi.org/10.11 23/jsep.31.2.152 